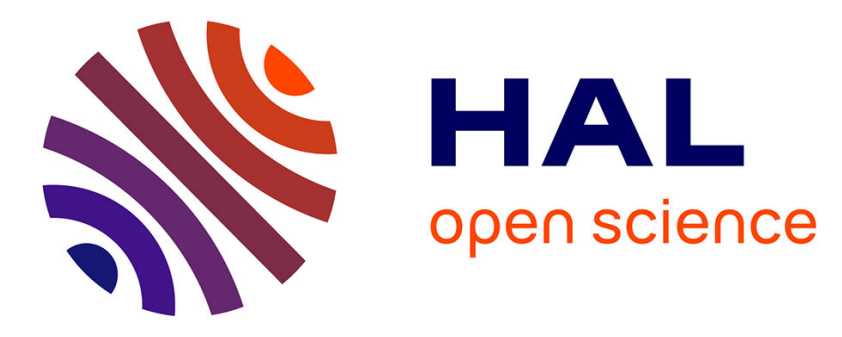

\title{
Simulation \& Emulation platform for smart grid technologies
}

\author{
Yassine Gangat, Nicolas Coquillas, Dominique Grondin, Michel Benne, \\ Jean-Pierre Chabriat, Taher Issoufaly
}

\section{- To cite this version:}

Yassine Gangat, Nicolas Coquillas, Dominique Grondin, Michel Benne, Jean-Pierre Chabriat, et al.. Simulation \& Emulation platform for smart grid technologies. Control, Electronics, Renewable Energy and Communications - ICCEREC, Dec 2018, Bandung, Indonesia. hal-01994072

\section{HAL Id: hal-01994072 \\ https://hal.univ-reunion.fr/hal-01994072}

Submitted on 25 Jan 2019

HAL is a multi-disciplinary open access archive for the deposit and dissemination of scientific research documents, whether they are published or not. The documents may come from teaching and research institutions in France or abroad, or from public or private research centers.
L'archive ouverte pluridisciplinaire $\mathbf{H A L}$, est destinée au dépôt et à la diffusion de documents scientifiques de niveau recherche, publiés ou non, émanant des établissements d'enseignement et de recherche français ou étrangers, des laboratoires publics ou privés. 


\section{Simulation \& Emulation platform for smart grid technologies}

\author{
Yassine Gangat \\ Energy, Electronic, and Processes \\ Laboratory $\left(\mathrm{LE}^{2} \mathrm{P}\right)$ \& Computer \\ Sciences and Mathematics Lab. (LIM) \\ University of La Réunion \\ Saint Denis, Réunion, France \\ yassine.gangat@univ-reunion.fr \\ Nicolas Coquillas \\ Energy, Electronic, and Processes \\ Laboratory ( $\left.\mathrm{LE}^{2} \mathrm{P}\right)$ \\ University of La Réunion \\ Saint Denis, Réunion, France \\ nicolas.coquillas@univ-reunion.fr
}

\author{
Dominique Grondin \\ Energy, Electronic, and Processes \\ Laboratory ( $\left.\mathrm{LE}^{2} \mathrm{P}\right)$ \\ University of La Réunion \\ Saint Denis, Réunion, France \\ dominique.grondin@univ-reunion.fr \\ Michel Benne \\ Energy, Electronic, and Processes \\ Laboratory ( $\left.\mathrm{LE}^{2} \mathrm{P}\right)$ \\ University of La Réunion \\ Saint Denis, Réunion, France \\ michel.benne@univ-reunion.fr
}

\author{
Taher Issoufaly \\ Energy, Electronic, and Processes \\ Laboratory $\left(\mathrm{LE}^{2} \mathrm{P}\right)$ \\ University of La Réunion \\ Saint Denis, Réunion, France \\ taher.issoufaly@univ-reunion.fr
}

\author{
Jean-Pierre Chabriat \\ Energy, Electronic, and Processes \\ Laboratory $\left(\mathrm{LE}^{2} \mathrm{P}\right)$ \\ University of La Réunion \\ Saint Denis, Réunion, France \\ jean-pierre.chabriat@univ-reunion.fr
}

\begin{abstract}
Energy management has become a very popular topic in the past few years, especially with the protection of the environment. The use and management of renewable energy sources (RES) has therefore become a necessity. In this context, innovative EMSs (Energy Management Systems) are required to bring a new way to monitor energy flows in micro grids. The interaction between physical and digital elements is relying on the use of Information and Communication Technologies (ICTs). A side effect is the appearance of Multi-Agent System (MAS) whose aim is to manage efficiently energy flows to reduce consumer bills, to minimize the use of fossil fuel in favor of RES. In this paper, we introduce "GYSOMATE", a simulation platform to test different management strategies, with the implementation of predictive tools and MAS to improve the EMS.
\end{abstract}

Keywords-smart grids, HIL, multi-agent system,

\section{INTRODUCTION (HEADING 1)}

Our modern society is based on energy. Whenever there is a power outage, most of our activities are paralyzed. On the one hand, the energy demands are increasing exponentially: growth in population, enhancement of building services and comfort levels, in conjunction with the rise of time spent inside buildings, have raised their energy consumption to the levels of transport and industry. [1]

On the other hand, continuation of fossil fuel uses will bring us to confront difficulties such as consumption of nonrenewable energy source, environmental alteration, etc. These issues show an unsustainable situation. [2]

Renewable energy sources (RES) such as solar or wind energy is the answer to this challenge. But these sources are intermittent and vary through the day. [3]

The Energy Management Systems (EMS) is a response to the energy challenges and the concern for the protection of the environment of industrialized and developing countries. It brings together techniques to reduce energy consumption for the sake of both financial economy and reducing the ecological footprint.

Reunion Island, which is located in a tropical area, provides a fertile ground for research in this domain.
Due to its small surface area $\left(2500 \mathrm{~km}^{2}\right)$, nuclear power generation cannot be implemented on the island: first, the unitary size is oversized in relation these needs; then, the maintenance of such a structure is impossible.

In addition, despite its small area, Reunion Island presents the same energy problems as in many countries of the world, including:

- The presence of many energy producers, from individual level to a collective one.

- A large number of consumers distributed in a nonhomogeneous way.

- A lot of different microclimates. [4]

- Different energy source types.

These parameters make the island an ideal place to generate research and innovation in the field of the rational use of energy.

A smart grid in Reunion Island should be built around these two following axes:

- an EMS that takes into account the topology of our electricity distribution networks

- a weather prediction tool that should be able to consider microclimates

Moreover, the intermittency, stochastic variability and low predictability of RES, including the solar resource, as well as the distributed nature of these units, require the development of intelligent, decentralized control strategies for all the elements such as conversion sources, storage systems and consumers.

Distributed energy resources (DER) expansion represents a change in the paradigm of power grids, making micro generation and storage units relevant, both in terms of sustainable development and demand side energy (DSE). In this context, the security of small and isolated to large-scale interconnected grids depends on an efficient EMS, resulting in a constrained optimization problem including two stages: unit commitment (UC) and economic dispatch (ED). Since the objective (e.g. balance equation) and constraints (technical limits, operational and security constraints) are expressed as linear functions, involving discrete and 
continuous variables, UC and ED can be formulated as a Mixed-Integer Linear Programming (MILP) problem. Commercial solvers as GUROBI, CPLEX or EXPRESS are able to solve MILP problems and considering thousands of variables and constraints.

Distributed control, monitoring and energy management have proved to achieve operational efficiency of interconnected DER, and many publications present multiagent systems (MAS) as one of the best technology for introducing distributed intelligence in large scale systems.

But developing smart grids in Reunion Island will require research \& development that suits the island's characteristic. It cannot be achieved with theories and simulation practices alone. Several smart grid simulations have already been compared, such as: MatPower, PSAT, InterPSS and GridLAB-D in [5], OpenDSS, GridLAB-D and APREM in [6]. But these simulations lack circumstances that physical experiment includes.

Developing a test-bed such as in [7] will be useful for testing control, communication but it won't suffice for a whole smart grid.

This study presents the first step in the development of an intelligent EMS taking into account the energy balance for an urban micro grid with battery storage, and using MAS to improve the communications scheme between the distributed facilities, and the commercial solver GUROBI to minimize cost and facility constraints. A testing platform called GYSOMATE (french acronym for Supervision, Dynamic Management and Optimization of Urban Micro grids for Island Electricity Self-sufficiency) is proposed. GYSOMATE will not only simulate but also emulate a fully customizable Smart grid. Thanks to this platform we will be able to test different EMS and prediction tools.

\section{DESIGN OF GYSOMATE's TESTING PlATFORM}

The purpose of our testing platform is to provide a sandbox in order to test several approaches of EMS and prediction. Our goal is not to provide the best EMS or prediction method, but rather to allow comparison between different configurations. This platform has been built from these 5 following modules:

- a Multi-Agent Systems (MAS)

- a Real-Time Simulator (OP4510 from Opal-RT)

- a nanogrid build from Raspberry-Pi \& Arduino mostly

- a Human Machine Interface (HMI).

- a NoSQL Database (InfluxDB)
The multi-agent system is not only a module, but it is also the binder between all modules as we will see further.

\section{A. The Multi-agent System}

Multi Agents Systems have already shown its strength in addressing issues related to complex systems involving ecological, economic and social dynamics [8]. In addition to this, Multi Agents offer formalizations that take into account both collective management and person-centered modeling [9]. The coupling between the individual and the collective, realized through the interactions, as well as the semantic richness of the spatialized environments make MAS a particularly adapted approach for our model of energy management [10] [11] [12].

The potency of our MAS architecture is that it's not only in charge of the EMS as in most of MAS such as Powermatcher and Volttron. It also serves as a prediction tool and a binder between GYSOMATE's components.

\section{1) MAS Architecture}

We have chosen an architecture that allows MAS to be the barycenter of our platform. At the beginning of the project, we chose the SKUAD framework (Software Kit for Ubiquitous Agent Development) developed by the Collective Adaptive Systems team of the LIM (Laboratory of Computer Science and Mathematics).

One of the reasons we have chosen this framework is that it has already all the leeway scope we need for GYSOMATE such as it includes Raspberry Pi \& Arduino API. Moreover, we can work together to develop new needed APIs.

But after analyzing the various articles dealing with the subject, we realized that JADE (Java Agent Development Framework) was one of the most used multi-agent platforms. We decided to create parallel MAS with JADE, which was not difficult because both JADE and SKUAD are written in Java.

An agent hierarchy as shown in the Fig.1 has been implemented to structure agents to fit our needs while being close to physical hardware distribution and network topology. There are 4 types of agents:

- Grid (in green): A Grid agent can "manage" another Grid agent or Supervisor agent.

- Supervisor (in yellow): A Supervisor agent always depends on a Grid agent. It "manages" Aggregator agents of different types.

- Aggregator (in blue): An Aggregator agent is intended to aggregate Device Agents of the same type. These aggregators are optional.

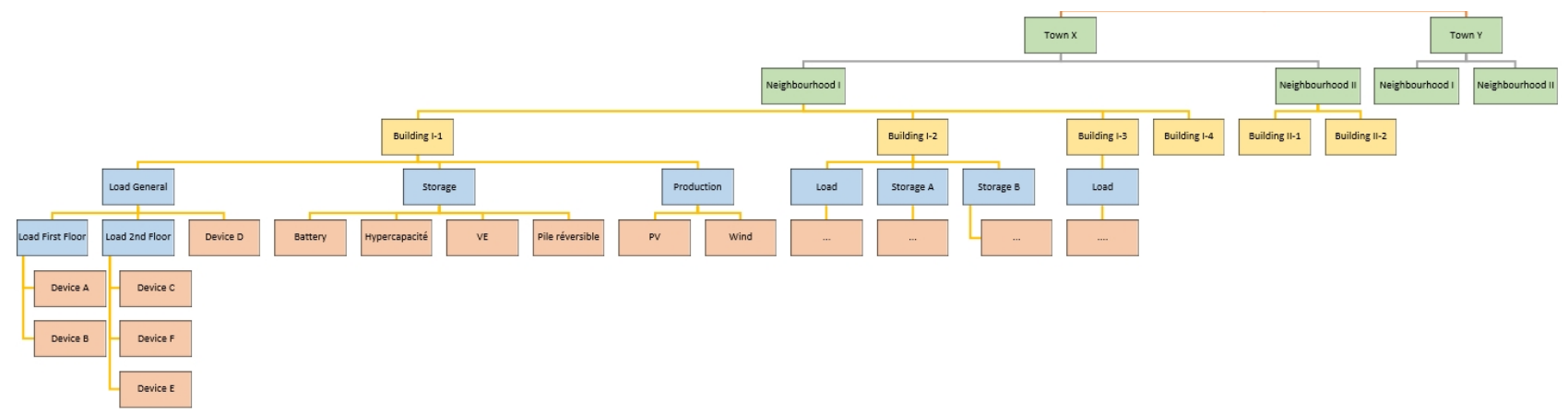

Fig. 1. Agent's hierarchy 
- Device (in orange): A Device Agent is an agent that is directly linked to a physical device that it controls (AC, light bulbs, switch, etc.). These devices could either be controlled or not.

The basic principle is each agent send back data to his "superior" and acts regarding its superior's orders. However, in some cases (i.e.: when the superior does not answer for example, etc.), the agents can communicate with other agents. The naming of the agents will be as follows:

- Town: Agent in charge of the city.

- Neighborhood: Agent in charge of a neighborhood.

- Building: Agent in charge of a building or at least the end-user (housing in a building). It can also be a battery or a PV farm.

- Load: all possible loads of the building.

- Storage: all types of energy storage (hydrogen, battery, etc.).

- Production: all types of energy production.

Our agents will first start with an 'initialization step' by checking its internal components (social links, physical links and battery status) before the agent starts its specific job: behaviors for either proactive activities (i.e.: an agent asks the current load of a battery) and reactive activities (i.e.: an agent will send his status whenever he is asked).

Each agent possesses some local multi-objective optimization method, controls the voltage and belongs to a global-objective and participates in voltage regulation of a complete system. All agents are coordinating together in a cooperative way.

\section{2) $M A S$ as an EMS}

After setting up our MAS for its basic functions, we focus on EMS. We have emulated (through Raspberry-PI) and simulated (through OP4510) a physical environment (i.e. a study case). In order to prove that our MAS will act as an EMS, we have formulated a very simple EMS that will be described in the chapter III.

The MAS has been built in such a way that we can easily replace the EMS by anything we want to code, as it has been separated from the kernel of the MAS.

\section{3) MAS as a prediction tool}

Our MAS has also been connected to our DB and is currently using Datamining's techniques such as classification and clustering. For each hour, we build a sliding horizon of classes. For each class, we have associated a set of behaviors adapted to it. This prediction method is used for both energy production and consumption.

In the same way as for the EMS, the prediction part of the agent has been clearly identified and could be changed by anything we want to implement.

\section{4) MAS as a binder}

In order to bind all the GYSOMATE modules together, we decided to "agentify" them. Through integration in the multi-agent's space, the OP4510 has now become a ubiquitous component and is now reachable by any agents. We have used the communication protocol library implemented in SKUAD, called Ubiquity. Indeed, it uses the concept of "space" (set of grouped elements interconnected) with the implementation of UDP protocol with an application layer that allows the management of sending and receiving packets along with the security of data sent on the channel. This mode of communication will enable the interaction between each element regardless of their type or their specification (database, JADE agent, simulator...). This generic aspect is a key factor for our proposed model.

Agents are also able now to access the DB and send logs to the HMI. Agents have also been implemented on Raspberry-pi and are now able to connect to Arduino in order to access real world's sensors and actuators.

Multi-agent system can operate in both real-time and simulated environment, giving us the best of both.

\section{B. Real-time simulator}

\section{1) Concept}

Today, many tools are emerging concerning the analysis of power systems. However, smart grids use case becomes more and more complex to meet the constraints in terms of energy efficiency. We find out that one tool cannot handle all the processes to achieve performance results. Therefore, the combination of several tools is required. In response to these growing challenges, real-time simulation platforms and suites are very suitable for integrating models, software and hardware components. This proposal is a concept approach that allows the analysis of large-scale scenarios. [13]

Many works in this domain first introduced a new method of rapid prototyping called HIL (Hardware-In-theloop Simulation), a simulation that implements the modeling of the studied environment and the physical equipment in closed loop, to bring more solutions for this challenge. The method was initially applied in the automotive industry [14] and has been used successfully to estimate the behavior of continuous analog processes under various control laws [15], [16]. The implementation of a HIL system is efficient in terms of computing power and speed of execution to simulate in real time the physical behavior of the systems with accuracy. Besides, development costs are significantly reduced by the introduction of a HIL system.

By definition, Hardware-In-the-Loop (HIL) characterizes a numerical simulation of the functioning of an electronic control unit (ECU) for which the hardware environment is simulated: the inputs and outputs of the tested system (hardware) are connected to a computer which reproduces the functioning of the environment

As explained in [17], HIL simulation is being increasingly used as an important design and development step in the manufacturing process of many industries [18]. HIL simulation provides a means for the operation of physical hardware, such as power components and control hardware, while interfaced to a computer simulation of the system in which the physical hardware is intended to function.

Opal-RT is leading testing equipment use for the hardware-in the loop and software-in-loop testing for various electro mechanical, electrical and power electronics system. Opal-RT is used for validating results of system simulations which is to be tested in real time.

\section{2) Architecture}




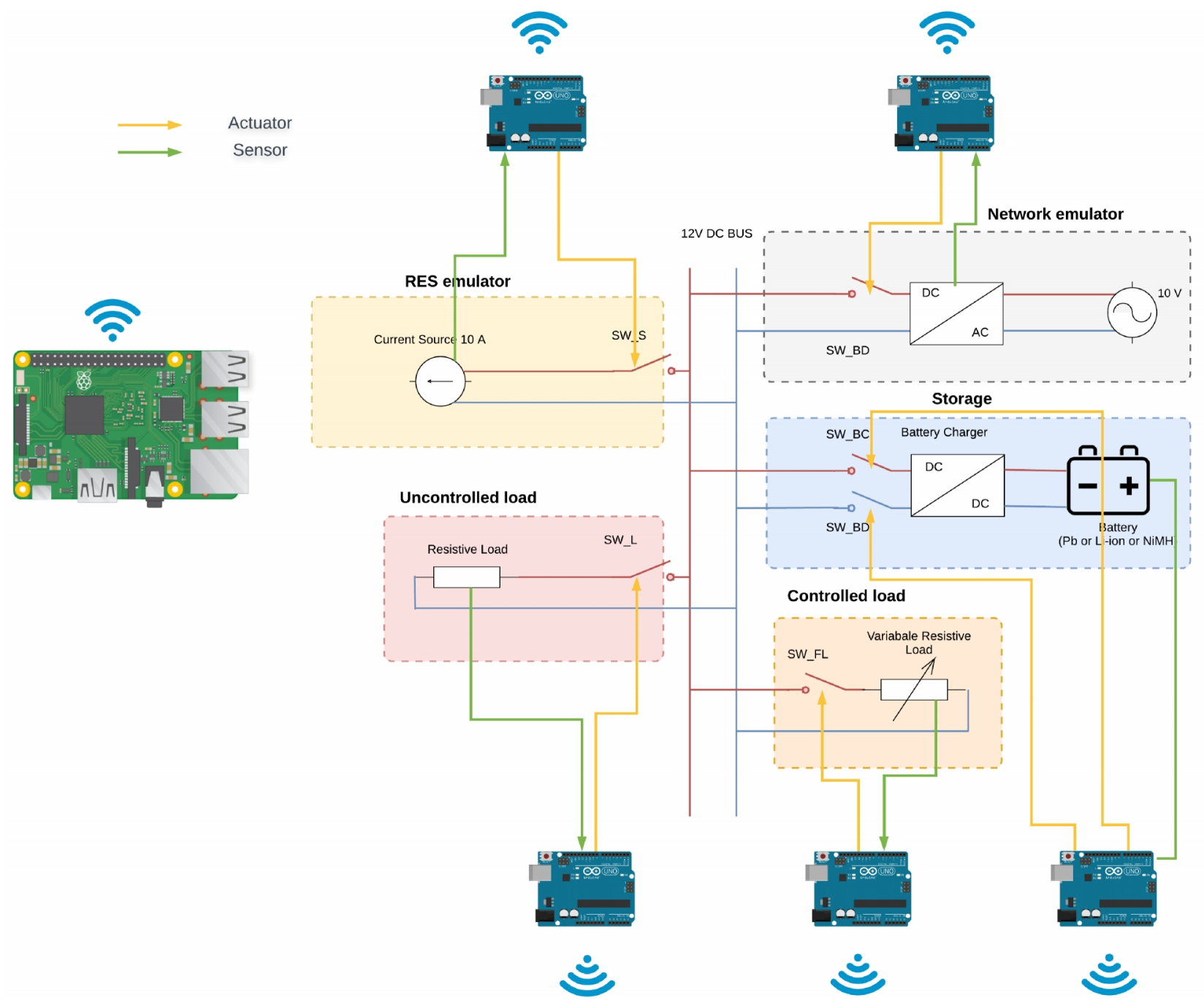

Fig. 2. Nanogrid

In fact, the real time simulation is realized with a realtime platform which is named RT-LAB, which is perfectly integrated with MathWork Matlab/Simulink.

RT-LAB converts Simulink models to implement them in a real-time environment, and then run them on one or more processors

There are two ways of communication between the host processors and the execution processors, the first via physical inputs/outputs, the second through an Ethernet connection.

\section{3) Interface}

The developed EMS must be able to act on the simulator. It is therefore necessary to build a communication tunnel which passes, on the one hand, the controls of the energy management system to the models simulated by RT-LAB, and on the other hand, which transfers the state variables of the simulator to the energy management system. To achieve this goal, we designed the architecture, to establish a socket for the model (service), then, to allow the agents, to pass the commands and the measures via this socket with a structured format of the data.

Each service (model) simulated in the RT-LAB has a physical counterpart in the energy management system; the correspondence is made by the alias of the actuator agent dedicated to the service.
The configuration of this system is done in a Json file with different parameters such as codes of instructions; data send or receive, agents aliases, etc.

\section{Nanogrid}

It is very complex to connect production, storage and consumption units for information feedback in real time and even more for piloting, particularly because of both juridical and technical aspect. Thus, we have decided to develop within the laboratory a connected and controllable nanogrid. This nanogrid would be built from:

- Emulators for RES,

- Emulators of devices consuming energy,

- Energy storage devices,

- Sensors and Actuators,

- Few electrical appliances connected and controllable within the laboratory (air conditioning, water heater).

The architecture deployed will be similar to that studied in the different cases of studies. Emulators, sensors, and actuators will be deployed using Arduino and Raspberry Pi microcontrollers. These devices are inexpensive and open, providing a greater degree of freedom in development. 
The nanogrid will operate on a $12 \mathrm{~V}$ voltage level for the emulated part. The storage device will be dimensioned to be integrated at this voltage level. The link with other electrical equipment will be via the energy management system and more particularly the multi-agent platform. This real nanogrid can be connected to other virtual nanogrid from the OP4510 real-time simulation.

The configuration of an elementary brick of this nanogrid is given in the Fig.2. The connection of microcontrollers via Wi-Fi has been considered because it allows a management of Arduino wirelessly by the Raspberry $\mathrm{Pi}$ in a transparent way.

The introduction of this nanogrid brings us several advantages. It allows us in particular to visualize live-effects of the EMS and to interact with the system in a real way. In addition, given the low cost of the equipment and the fact that it is only running on $12 \mathrm{~V} \mathrm{DC}$, the eventual damage will be limited in the case of a bad EMS.

\section{Human Machine Interface}

A multilevel HMI is under development. The target audience for this HMI is the following people:

- The end-user: this is a person who has access to a supervising agent and all agents underneath.

- The "neighborhood" responsible user: this is a person who has access to the first level of the grid agent, who is under the supervision of the supervisory agents. He will have access to only partial and/or anonymized information.

- The responsible user of the "city": this is a person who has access to the second level of agents' grid, which is under the responsibility of other agents' grids.

For each user, the HMI has several views:

- Located view: a view that shows agent localization, available actions and logs.

- Graphic view: a view with mostly graphics and alert trigger

- Dashboard: a simple view that could also be rendered as a WebApp, with minimal information

- Configuration: this where we can configure rules for the ESM or prediction.

The final HMI is still under development but the prototype we used for our testing is operational.

The HMI is initialized by an XML file that contains the scenario configuration (id, nature, information of each agent and elements) and is fed by data and logs from agents. It can also send orders or requests to some agents.

\section{NoSQL Database}

In our project, we have several types of data, from different sources:

1. Energy-related Data (production, consumption and storage) from our partners,

2. Energy related Data and logs from our simulations and emulations,
3. Energy related Data and logs from our Laboratory (sensors, prediction, etc.)

Energy production, consumption and storage data are time series with values. The logs are also time series containing text. Among the Time Series Data Bases, InfluxDB was chosen particularly because several services are already ready: graphics, export, calculation of averages, API web/rest, management of alert, etc. InfluxDB comes with a stack that includes all the tools needed to set up the DB. The Table 1 shows a summary of our partner's and our Lab's data.

TABLE I. OUR PARTNER'S AND OUR LAB'S DATA

\begin{tabular}{l|c|l|c|c}
\hline \multicolumn{1}{c|}{ Type } & $\begin{array}{c}\text { Number } \\
\text { of sites }\end{array}$ & \multicolumn{1}{|c|}{ Settings } & $\begin{array}{c}\text { Time } \\
\text { step }\end{array}$ & Period \\
\hline $\begin{array}{c}\text { Photovoltaic } \\
\text { Production }\end{array}$ & 27 & $\begin{array}{l}\text { Power } \\
\text { (Converter } \\
\text { output })\end{array}$ & $10 \mathrm{~min}$ & $\begin{array}{l}\text { Up to 6 } \\
\text { years }\end{array}$ \\
\hline Sun power & 14 & $\begin{array}{l}\text { Irradiance, } \\
\text { Temperature }\end{array}$ & $\begin{array}{l}10 \mathrm{~min} \\
1 \quad \mathrm{~min} \\
\left(\mathrm{LE}^{2} \mathrm{P}\right)\end{array}$ & $\begin{array}{l}\text { Up to 10 } \\
\text { years } \\
\left(\mathrm{LE}^{2} \mathrm{P}\right)\end{array}$ \\
\hline $\begin{array}{l}\text { Tertiary } \\
\text { consumption }\end{array}$ & 3 & $\begin{array}{l}\text { Energy and } \\
(\text { General } \\
\text { AC) }\end{array}$ & $\begin{array}{l}\text { More than } \\
1 \text { year }\end{array}$ \\
\hline
\end{tabular}

\section{Preliminary Result}

To put forward a first version of our system, we decided to focus on an elementary brick composed of one element of storage, production and consumption. This environment is presented with the Fig.3. There is a house wired with the utility grid which represents the consumption part equipped with a photovoltaic plant that aims to produce energy and a battery for the storage. Indeed, it is a very simple example, but it will assure us that everything is working together.

The architecture in our system to reproduce the elemental brick will use the OPAL-RT simulator which creates all physical elements by interconnecting them. For each physical element, we will associate them with an agent implemented by our multi-agent part. Therefore, we'll have a battery agent plugged to the battery, a charge agent linked with the consumption element and a PV agent for the photovoltaic plant. A supervisor agent will be created to manage these previous listed agents.

The scenario is described as follows: the charge part is simulated with a consumption profile save into a file read by the simulator to generate consumption values according to time. For the generation of photovoltaic production value, we used real data collected in our database, recorded in a file and read according to time by the simulator. Periodically, the battery agent will ask for the current level of the battery. The charge agent will do the same process by collecting the

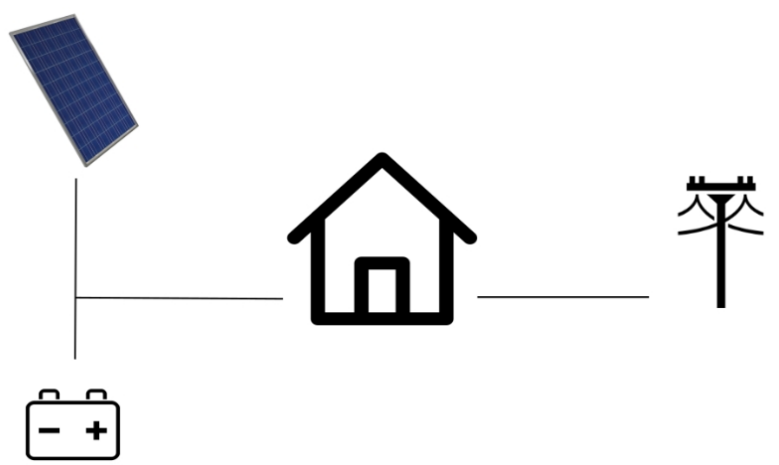

Fig. 3. Study case 


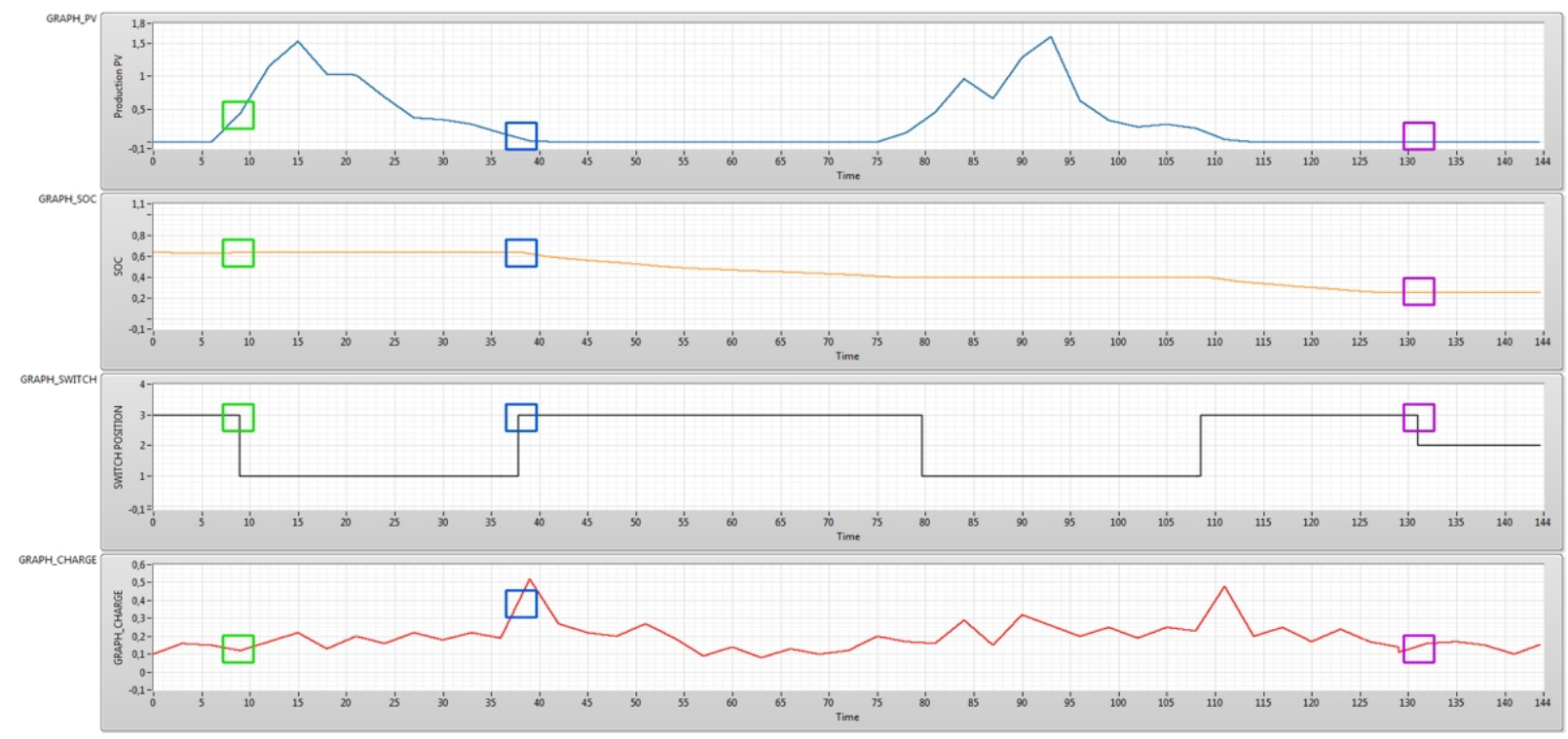

Fig. 4. Results

generated consumption. Finally, the PV agent will get the production values by interacting with the photovoltaic physical element in the simulator. All of this information will be sent to the supervisor. After analyzing them, the latter will monitor the energy source by interacting with the photovoltaic production and the battery. Indeed, he will choose to use the energy of the photovoltaic production or the energy stored in the battery according to the consumption curve simulated.

The preliminary results are described with the Fig.4. There are four curves. The first one represents the photovoltaic production according to time. The second one refers to the state of charge of the battery. The third curve is the position of the switch button and the last indicates the consumption of energy according to the time.

The supervisor agent can take three actions with a switch button: use the production energy (position 1), use the energy stored in the battery (position 3 ) or take to the energy from the electrical network (position 2). At the beginning, the energy stored in the battery is used.

We can see that when the photovoltaic production increases and is superior to the consumption, the agent will switch the position to 1 and take this source of energy to meet the consumption as shown with green boxes.

The second case is highlighted with blue boxes. There is a peak of consumption and the production of photovoltaic panels is low. The only solution is to take energy from the battery. This is the reason why the supervisor agent switches the position to 1 .

Finally, the last situation is represented by purple boxes. In this scenario, the production of photovoltaic is not enough to meet the need of the consumption. Besides, the energy stored in battery is low. The action taken by the supervisor agent will consist of plugging to the electrical network to ensure the necessary needs for consumption (switch position to 2).

These results clearly show us that all modules of our platform were well connected through a simplistic model of elemental brick. This has also shown the impact of the multiagent system for better energy management. These tests ensure the robustness of the basic elements of our system which will allow the development of other more complex models in the future.

\section{CONCLUSION \& PERSPECTIVES}

In recent years, EMS (Energy Management System) represented centralized systems with pre-defined and nondynamic algorithms. The introduction of multi-agent systems, which is very popular, has led to the restructuring of this type of system in order to monitor, control and optimize the generation and transmission of energy sources. New architectures tend towards a decentralized approach with the competence of the agents to act according to the environment in which they are located.

Plethora of energy management systems are presented in the literature. In this paper, we focused on the development of a testing platform called "GYSOMATE". The aim is to implement a generic EMS with the use of multi-agent system allowing the interconnection of different entities. The preliminary results emphasize the success of the interconnection of entities through sending and receiving packets with the same protocol of communication using a simplistic model of elemental brick.

Our next step will be to reflect the complexity of realworld smart grid including unpredictable renewable energy sources by using more complex scenarios as illustrated in the Fig 5.

In the future, our generic system will improve with the use of predictive algorithms to help agents for their decision making. The latter will propose different methods such as classification, determinist approach, game theory or stochastic process. The aim is to simulate the behavior of our agents using a set of algorithms and analyze the results to choose the better one according to the context. Besides, implementation of optimization algorithms is being studied whose first experiment was conducted with the GUROBI solver. Finally, the introduction of negotiation process between agents for the energy management is also planned. In this case, there is no supervisor agent that sends orders to inferior agents. All agents will be at the same level and will interact with each other to find themselves in the most accurate solution to optimize sources of energy. 


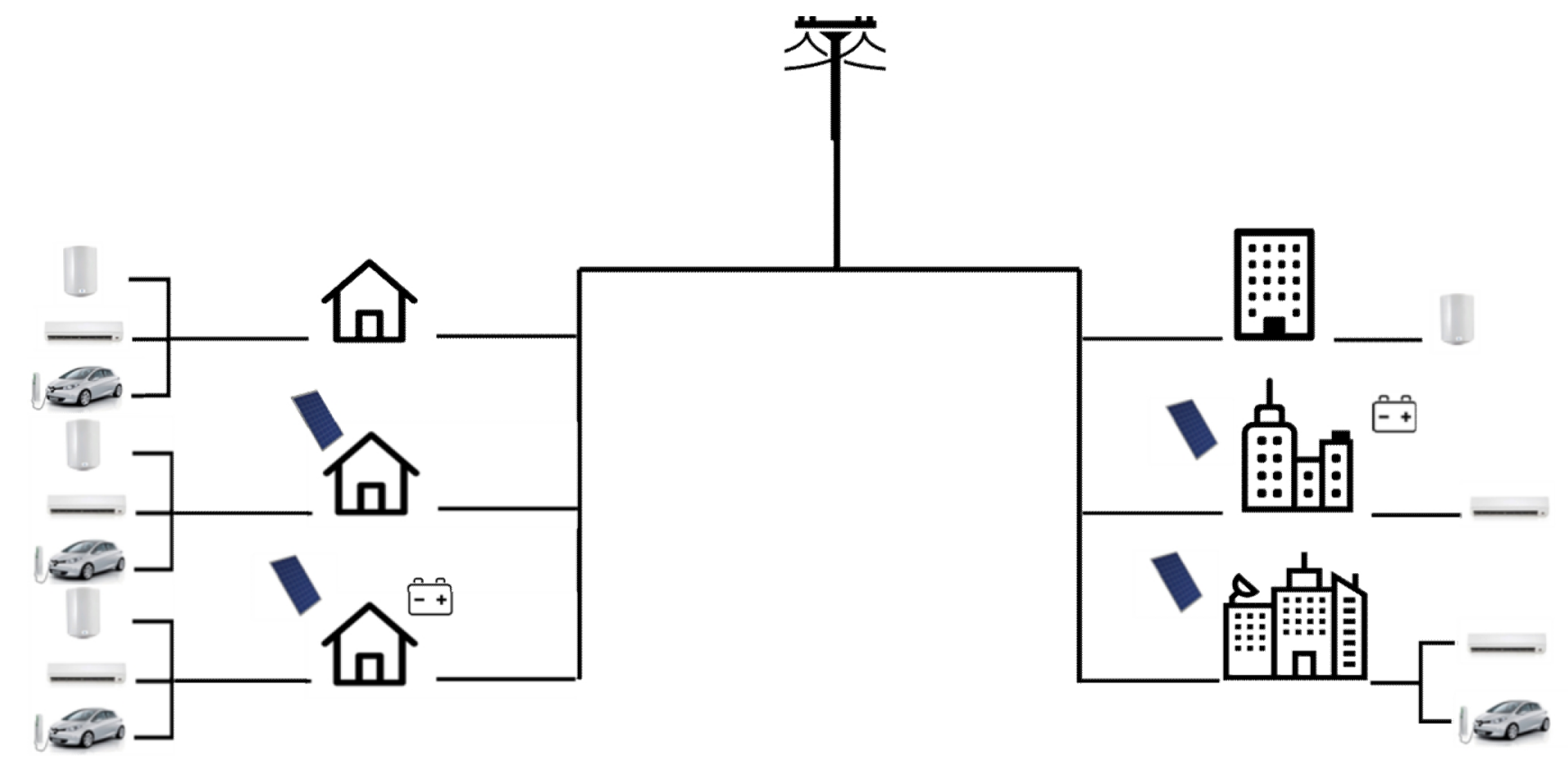

Fig. 5. Perspectives

To conclude, "GYSOMATE" platform aims to become a generic tool allowing us to easily plug different entities and analyze the results of the different simulations to have a better overview of agents' behavior and actions taken while finding the right compromise according to the context/constraints.

\section{ACKNOWLEDGMENT}

Special acknowledgments go to the European Regional Development Funds (ERDF) and the Regional council of Reunion for GYSOMATE project funding, the project's partners Corex Solar, TEEO. We also address special thanks to Dr. Denis Payet, from the Lab. of Computer Science and Mathematics (LIM) of University of La Reunion for the SKUAD framework.

\section{REFERENCES}

[1] Pérez-Lombard, L., Ortiz, J., \& Pout, C. (2008). A review on buildings energy consumption information. Energy and buildings, 40(3), 394-398

[2] Atilgan, B., \& Azapagic, A. (2015). Life cycle environmental impacts of electricity from fossil fuels in Turkey. Journal of Cleaner Production, 106, 555-564.

[3] Carrasco, J. M., Franquelo, L. G., Bialasiewicz, J. T., Galván, E., PortilloGuisado, R. C., Prats, M. M.,... \& Moreno-Alfonso, N. (2006). Power-electronic systems for the grid integration of renewable energy sources: A survey. IEEE Transactions on industrial electronics, 53(4), 1002-1016.

[4] David, M., Andriamasomanana, F. H. R., \& Liandrat, O. (2014). Spatial and temporal variability of PV output in an insular grid: Case of Reunion Island. Energy Procedia, 57, 1275-1282.

[5] Pöchacker, M., Sobe, A., \& Elmenreich, W. (2013). Simulating the smart grid. arXiv preprint arXiv:1304.2503.

[6] Moffet, M. A., Sirois, F., \& Beauvais, D. (2011). Review of open source code power grid simulation tools for long-term parametric simulations. CanmetENERGY, Tech. Rep., 137.

[7] Leskarac, D., Bennett, C., Moghimi, M., Stegen, S., \& Lu, J. (2015, November). Testing facility for research and development of SmartMicroGrid technologies. In Power and Energy Engineering Conference (APPEEC), 2015 IEEE PES Asia-Pacific (pp. 1-5). IEEE.
[8] Bousquet, F., Barreteau, O., Le Page, C., Mullon, C., \& Weber, J. (1999). An environmental modelling approach: the use of multi-agent simulations. Advances in environmental and ecological modelling, $113,122$.

[9] Ferber, J., \& Weiss, G. (1999). Multi-agent systems: an introduction to distributed artificial intelligence (Vol. 1). Reading: AddisonWesley.

[10] Gangat, Y., Duizabo, A., Courdier, R., Payet, D., Bessafi, M., \& Chabriat, J. P. (2016, October). Simulation of microgrids using a multi-agent system and measurements of solar ressources on the island of Reunion (original title : Simulation de microgrids à l'aide d'un système multi-agents et de mesures de gisements solaires sur l'ile de La Réunion.) In JFSMA'16 (pp. 247-248). Cepadues.

[11] Gangat, Y., Courdier, R., \& Payet, D. (2009, October). Energy management of a territory-a multi-agent simulation approach (original title: Aménagement énergétique d'un territoire-une approche par simulation multi-agents). In Journées Francophones Systèmes MultiAgents (JFSMA'09) (pp. 237-240). Cepadues.

[12] Labeodan, T., Aduda, K., Boxem, G., \& Zeiler, W. (2015). On the application of multi-agent systems in buildings for improved building operations, performance and smart grid interaction-A survey. Renewable and Sustainable Energy Reviews, 50, 1405-1414.

[13] Opal-RT, http://www.opal-rt.com, accessed September 2018

[14] Wei Deng, Wei Pei, Ziqi Shen, Zhenxing Zhao, "IEC 61850 based testbed for micro-grid operation control and protection", Electric Utility Deregulation and Restructuring and Power Technologies (DRPT) 2015 5th International Conference on, pp. 2154-2159, 2015.

[15] Patricio Cortes, David O. Boillat, Johann W. Kolar, "Phase-oriented control of a modular 3-Phase 3-level 4-leg inverter AC power source supplying floating or grounded loads", Energy Conversion Congress and Exposition (ECCE) 2013 IEEE, pp. 1357-1363, 2013.

[16] Patricio Cortes, David O. Boillat, Hans Ertl, Johann W. Kolar, "Comparative evaluation of multi-loop control schemes for a highbandwidth AC power source with a two-stage LC output filter", Renewable Energy Research and Applications (ICRERA) 2012 International Conference on, pp. 1-10, 2012.

[17] Ren, W., Sloderbeck, M., Steurer, M., Dinavahi, V., Noda, T., Filizadeh, S., ... \& Belanger, J. (2011). Interfacing issues in real-time digital simulators. IEEE Transactions on Power Delivery, 26(2), 1221-1230.

[18] Dufour, C., Abourida, S., \& Belanger, J. (2005, November). Hardware-in-the-loop simulation of power drives with RT-LAB. In Power Electronics and Drives Systems, 2005. PEDS 2005. International Conference on (Vol. 2, pp. 1646-1651). IEEE. 